\title{
Analysis of the Working Characteristics of the Natural Draft Cooling Tower on the Laboratory Model \\ ${ }^{1}$ Ayrat I. Badriev, ${ }^{2}$ Vilen N. Sharifullin, ${ }^{3}$ Andrew V. Sharifullin \\ ${ }^{1}$ Kazan Federal University \\ ${ }^{2}$ Kazan State Power Engineering University \\ ${ }^{3}$ Kazan National Research Technological University \\ Email: aibadriev@gmail.com
}

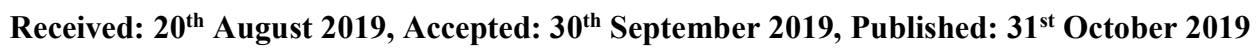

\begin{abstract}
The summer season becomes difficult for chimney-type cooling tower. Due to the hot atmospheric air entering the apparatus, insufficient heat removal occurs, which means undercooling of water. Ultimately, this leads to a decrease in the power of the steam turbine of a thermal power plant. In the summer, an experimental study of the irregularity of the irrigation of the cooled water by the natural cooling tower was carried out. A significant irregularity in the density of irrigation over the cross section of the apparatus was established. The regression dependences of the temperature difference and cooling power are constructed taking into account the irregularity of the irrigation density. The obtained performance characteristics are tested on a laboratory model of the cooling tower.

It is established that the nature of the regression models of temperature difference and cooling power from the density of irrigation of the natural cooling tower and its models are of the same nature. Thus, in a laboratory setup, confirmation of the performance of a full-scale cooling tower was obtained. Comparing the nature of the dependences of the laboratory model and the dependences of the cooling tower, it should be noted that the dependences of the temperature difference are expressed parabolic, and the cooling capacity on the density of irrigation cubic equation. The performance characteristics of a full-scale cooling tower allow us to judge its effectiveness by its sections, functioning in conditions of irregular irrigation.
\end{abstract}

Keywords

Cooling Tower, Irregularity of Irrigation, Performance, Laboratory Installation, Cooling Efficiency.

\section{Introduction}

For the cooling towers, the summer season becomes a difficult period $[1,2]$.

Due to the heating of the atmospheric air entering the apparatus, which is the refrigerant of the evaporation process, the temperature of the cooled water increases. Therefore, in order to achieve the required final water temperature, manufacturers resort to lower hydraulic loads. Presumably, the reason for the decline in cooling efficiency may be uneven distribution of irrigation in the cooling tower. Therefore, it was decided to conduct an experimental study of the operating characteristics of the cooling tower taking into account the uneven distribution of water irrigation over the cross section of the apparatus.

\section{Methods}

In the summer season, at an ambient temperature of $25-31{ }^{\circ} \mathrm{C}$, a hydraulic load of $8400-12000 \mathrm{t} / \mathrm{h}$, at the functioning cooling tower BG - 2600 of a thermal power station (Fig. 1), an analysis of water irrigation was performed. Three parallel experiments were carried out, during which irrigation density measurements were taken over the cross section of 12 sections of the apparatus.

In each section, measurement positions were indicated. 


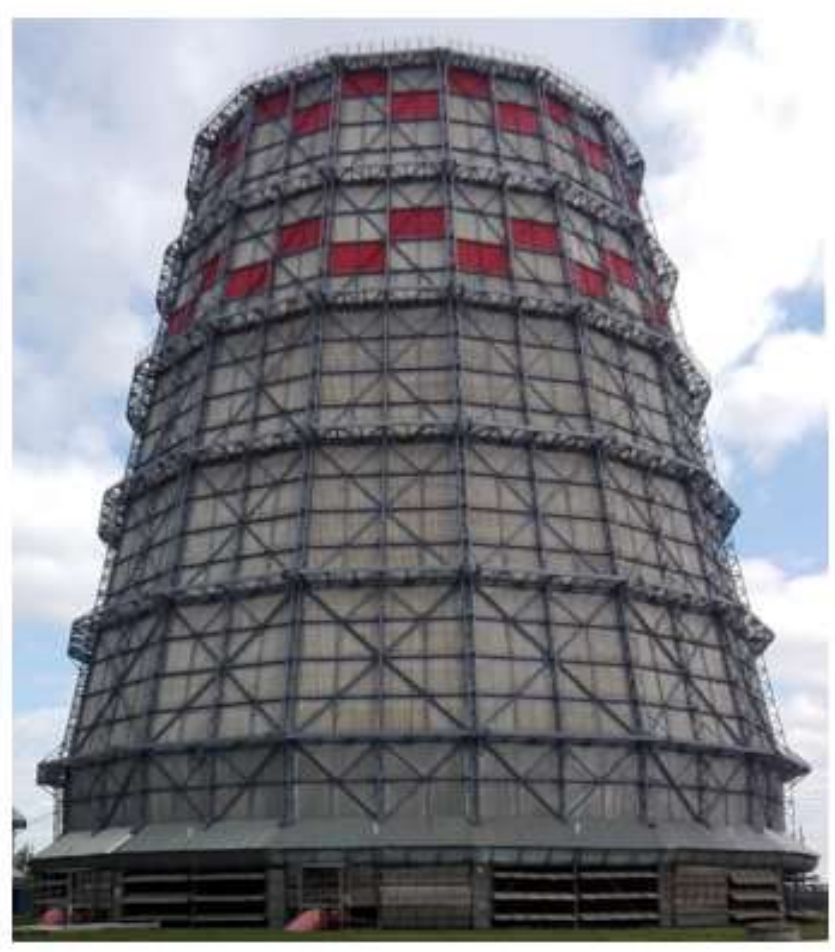

Fig. 1: Cooling Tower BG-2600

The measurement technique consisted of the following: in the positions of each section of the apparatus, with the help of a telescopic pipe at the end of which a measuring vessel is fixed, the stopwatch obtained the time of filling this container with water. According to the data obtained, the irrigation densities of each section of the cooling tower were calculated. In each half of the section, 7 positions were selected. A large amount of experimental data was processed by a statistical method [3]. As a result, it was found that with an average density of irrigation of the cooling tower of $3.41 \mathrm{~m}^{3} / \mathrm{m}^{2} \cdot \mathrm{h}$, the standard deviation was $1.13 \mathrm{~m}^{3} / \mathrm{m}^{2} \cdot \mathrm{h}$ or $33 \%$ of the average value. An analysis of the distribution of irrigation density revealed the causes of irregularity in irrigation. These include: malfunction of pipelines and nozzles of the water distribution system, improper location and damaged condition of the irrigation units of the cooling tower.

Along with measurements of irrigation density, at the same time, water temperature was taken at the level of the nozzles of the water distribution system and at the basin level of 12 sections of the cooling tower. Using a digital thermometer with a remote sensor, lowered into a measuring vessel, the instantaneous temperature of the cooled water was recorded. [4,5]

If we assume that the sections of the cooling tower are identical with respect to each other, then the experimental indicators of the sections can be combined to build a working characteristic. Thus, based on the obtained experimental data on the irrigation density and the water temperature difference, a regression model of the dependence of the temperature difference on the irrigation density was constructed taking into account the irregularity of the irrigation density (Fig. 2). 


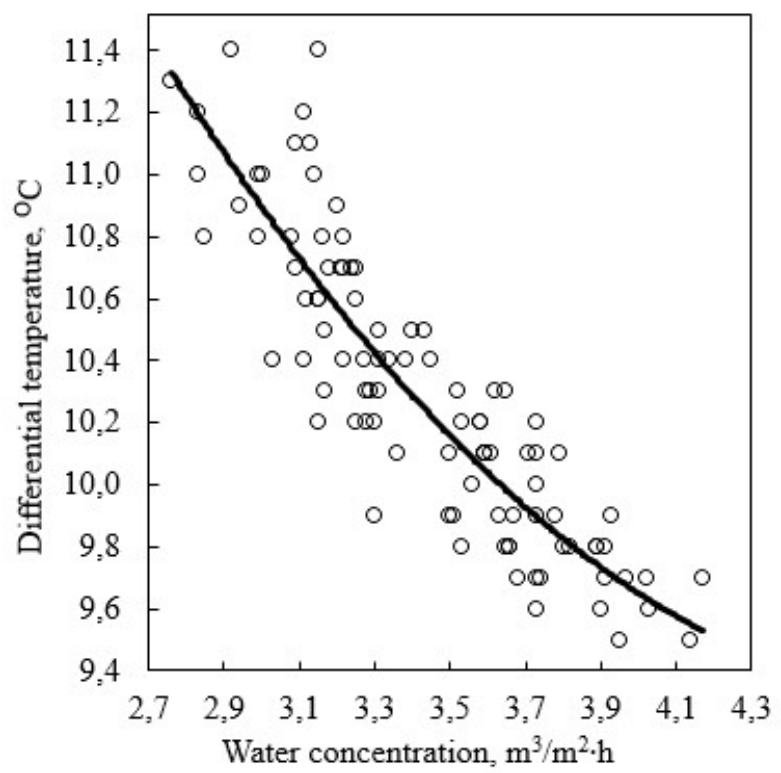

Fig. 2: Temperature Characteristic taking into Account the Irregularity of the Irrigation Density of the Cooling Tower

The dependence is described by the parabolic type regression equation:

$$
\Delta T=0,46 q^{2}-4,46 q+20,14
$$

where $\Delta \mathrm{T}$ is the temperature difference, oC; $q$ - irrigation density, $\mathrm{m}^{3} / \mathrm{m}^{2} \cdot \mathrm{h}$.

The correlation coefficient of the regression equation $(3,4)$ was 0.78 , which indicates a high degree of connection. The performance characteristic reflects the degree of cooling of water and allows, by density of irrigation, to assess the cooling capacity of the apparatus in sections. At the same time, an important criterion for evaluating the effectiveness is the effect of the distribution of irrigation density on the evaporation capacity.

So, based on the obtained experimental values of the density of irrigation and temperature difference, the cooling capacities of the cooling tower are calculated by the formula

$$
R=q \cdot \Delta T \text {. }
$$

Based on the calculations by formula (2), a cooling characteristic is constructed taking into account the irregularity of the irrigation density (Fig. 3).

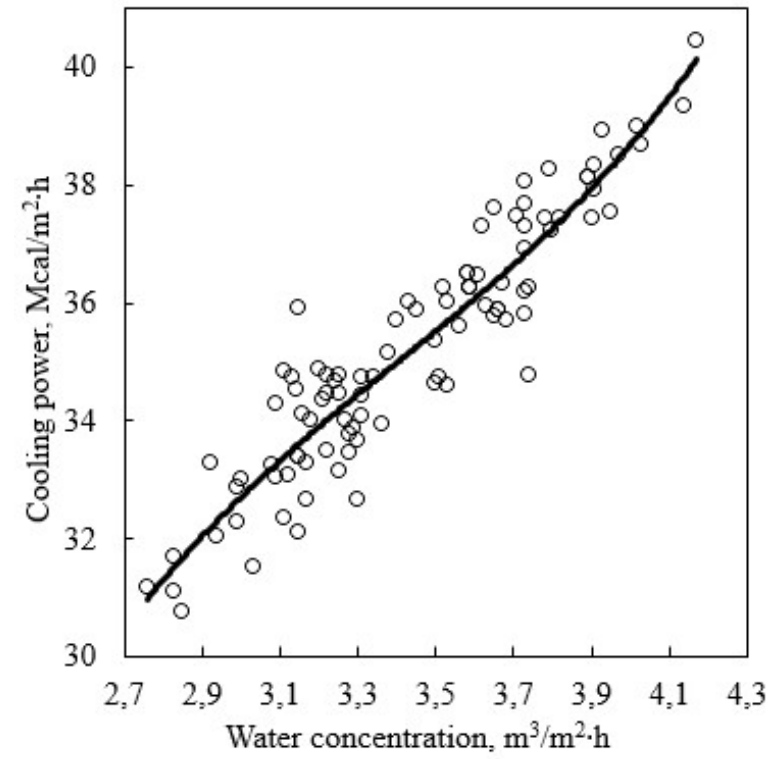

Fig. 3: Temperature Characteristic taking into Account the Irregularity of the Irrigation Density of the Cooling Tower 
Analysing the dependence of the cooling capacity, it can be found that it has a step-like character: from 2.7 to 3.3 $\mathrm{m}^{2} \cdot \mathrm{h}$ the cooling capacity curve is declining; after $3.8 \mathrm{~m}^{3} / \mathrm{m}^{2} \cdot \mathrm{h}$, the cooling capacity starts to grow again.

From the point of view of mathematical analysis, if, when processing experimental data, the dependence of the temperature difference on the irrigation density (Fig. 2) is expressed by a parabolic equation, then the cooling power, depending on the irrigation density, will be expressed by a cubic parabola (Fig. 3). The obtained regression model of the cooling characteristic allows us to analyse the cooling ability of the cooling tower, which determined the "weak" and "strong" sections. Moreover, knowing the density of the irrigation section, you can evaluate the heat removal of a particular section of the apparatus.

Despite the theoretically high correlation coefficient of the temperature characteristic and the cooling characteristic, and due to external influences affecting the course of the cooling process in the apparatus, it was additionally decided, experimentally, to analyse the performance of the tower in a laboratory setup. [6]

To confirm the established dependencies of the tower cooling tower, experimental studies were conducted at the laboratory installation of the research laboratory «Heat Source - Heat Network» of Kazan State Power Engineering University. The central apparatus of the laboratory model for reverse cooling was a $1.25 \mathrm{~m}$ high cooling tower with an irrigation area of $0.3 \mathrm{~m}^{2}$, which is 51 times smaller than the full-scale natural cooling tower BG-2600.

The installation serves to assess the effectiveness of water-cooling, the main structural elements of which are a pyramidal exhaust tower, an irrigator, a circulating pump, a fan, and brass tubes (Fig. 4).

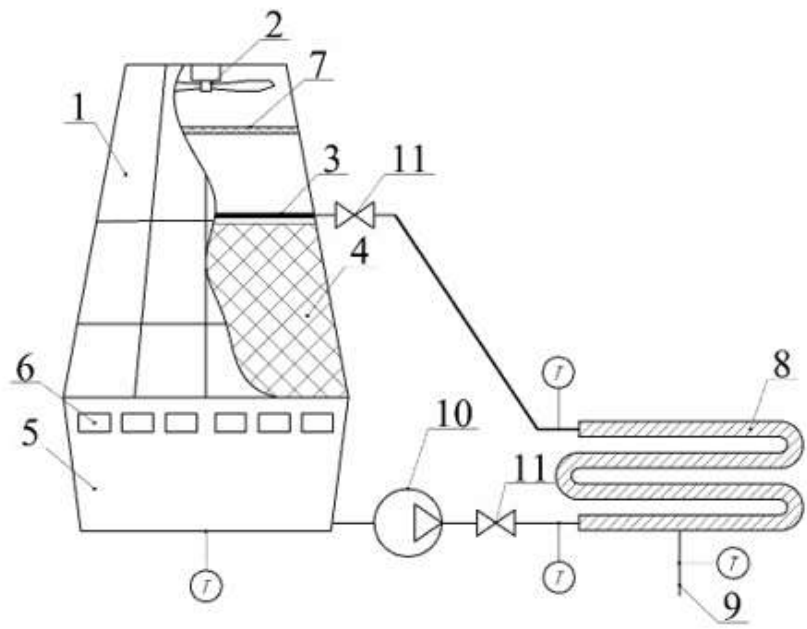

Fig. 4: Scheme of the Laboratory Model

( 1 - exhaust tower; 2 - fan; 3 - water distribution device; 4 - sprinkler; 5 - drainage basin; 6 - air duct windows; 7 - droplet eliminator; 8 condenser tubes; 9 - tube heating system; 10 - circulation pump; 11 - valve; $\mathrm{T}$ is a thermocouple. )

According to the hygrometer, at an ambient temperature of $24.5^{\circ} \mathrm{C}$ and a relative humidity of $79 \%$ using a dry thermometer, measurements of the temperature drop and air velocity depending on the density of irrigation were performed on the experimental setup. The hydraulic load on the working range of the circulation pump ranged from $0.99-1.98 \mathrm{~m}^{3} / \mathrm{h}$.

The experimental procedure was as follows: water (about 20 liters) was collected in the installation bowl to circulate in the system loop. The first stage of the circulation pump was selected with a power of $20 \mathrm{~W}$ and a corresponding water flow rate from 0.99 to $1.26 \mathrm{~m}^{3} / \mathrm{h}$. Within the operating range, the water flow was regulated using a valve installed on the water supply pipe to the unit. Four valve positions were recorded: a rotation of 45 about, 90 about, 135 about and 180 about.

Similarly, in the following stages, the $2 \mathrm{nd}(40 \mathrm{~W})$ and $3 \mathrm{rd}(60 \mathrm{~W})$ stages of the circulating pump were selected, with a water flow range from 1.35 to $1.62 \mathrm{~m}^{3} / \mathrm{h}$ and from 1.71 to $1.98 \mathrm{~m}^{3} / \mathrm{h}$, respectively.

The initial water temperature was measured using a conventional thermocouple mounted on a brass tube simulating a bundle of condenser tubes. In a tube entwined with a heating cable, the water temperature was maintained up to $30 \mathrm{oC}$. A digital thermometer, lowered into the installation bowl, measured the instantaneous value of the final temperature of water cooling.

When the irrigation area of the installation is $0.3 \mathrm{~m}^{2}$, and the values of water consumption, the corresponding values of the irrigation density are calculated:

$q=\frac{G}{S}$ 
where $\mathrm{q}$ is the irrigation density, $\mathrm{m} 3 / \mathrm{m} 2 \cdot \mathrm{h}, \mathrm{G}$ is the water consumption for the installation, $\mathrm{m} 3 / \mathrm{h}, \mathrm{S}$ is the irrigation area of the installation, $\mathrm{m} 2$.

So, the dependences of the temperature difference on the density of irrigation, with the corresponding steps of the circulating pump, are obtained.

The results were combined into a general dependence of the temperature characteristic of the laboratory setup (Fig. 5).

Obviously, the temperature characteristic is an inverse nonlinear dependence.

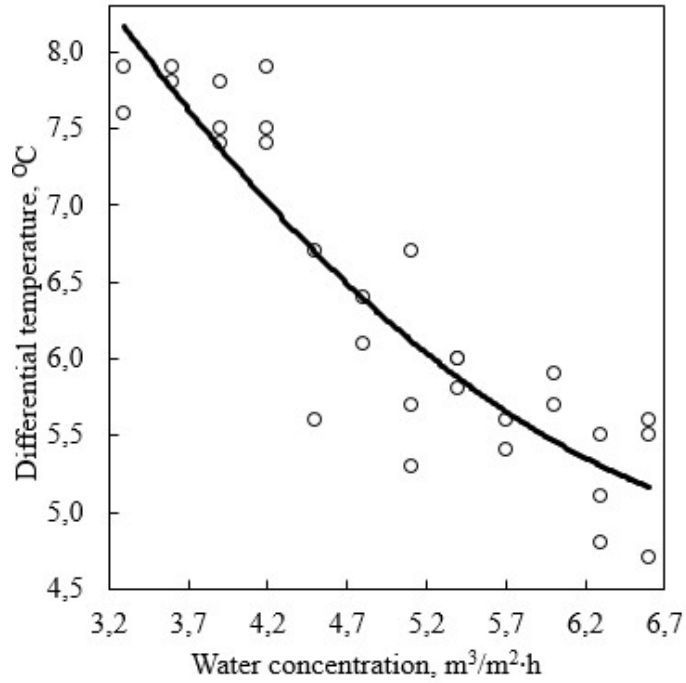

Fig. 5: Temperature Characteristic of the Laboratory Model

The dependence is described by the parabolic type regression equation:

$$
\Delta T=0,15 q_{u}^{2}-2,4 q_{u}+14,5
$$

where $\Delta \mathrm{T}$ is the temperature difference of the laboratory model, ${ }^{\circ} \mathrm{C} ; q_{u}$ - irrigation density of the laboratory setup, $\mathrm{m} 3 / \mathrm{m}^{2} \cdot \mathrm{h}$.

Thus, the experiment showed the similarity of the operating characteristics of the cooling tower and laboratory model. In addition, the correlation coefficient of the dependence of the temperature drop on the irrigation density of the laboratory setup was 0.83 , which indicates a high degree of connection between these parameters of the temperature difference and the irrigation density.

Applying the cooling capacity calculation formula (2), their values were calculated; the data were grouped and analysed using regression and correlation analysis. The results are combined to construct the dependence of the cooling characteristic on the irrigation density of the laboratory model (Fig. 6).

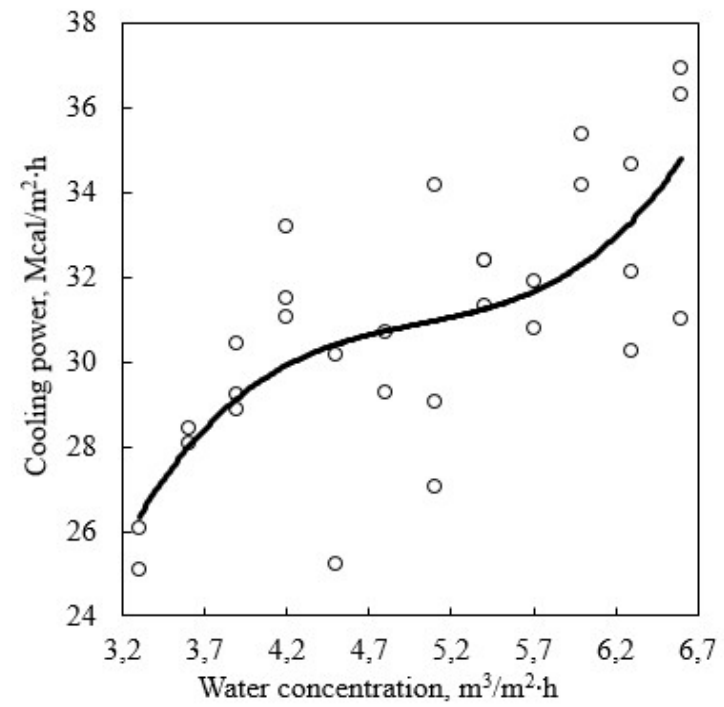

Fig. 6: Cooling Characteristic of the Laboratory Model 
Similarly, to the cooling power of the cooling tower, the obtained dependence has a stepwise character.

\section{Results and Discussion}

Thus, in the laboratory model, confirmation of the performance of a full-scale cooling tower was obtained. Comparing the nature of the dependences of the laboratory model and the dependences of the cooling tower, it should be noted that the dependences of the temperature difference are expressed parabolic, $[7,8]$ and the cooling capacity on the density of irrigation cubic equation. The only difference is that the operating characteristics of the cooling tower are built taking into account the irregularities of the flows involved, and the operating characteristics of the laboratory model with a uniform distribution of flows, since there are practically no irregularities in laboratory conditions.

\section{Summary}

The obtained temperature and cooling characteristics of the cooling tower make it possible to evaluate the efficiency taking into account the uneven distribution of the irrigation density distribution of the cooling tower.

\section{Conclusions}

The operating characteristics of the cooling tower, taking into account the irregularity of the irrigation density, make it possible to evaluate the efficiency of the tower-cooling tower by actual parameters and introduce corrections when planning the hydraulic load at thermal power plants. $[9,10]$

\section{Acknowledgments}

The work is performed according to the Russian Government Program of Competitive Growth of Kazan Federal University.

\section{References}

[1] L.D. Berman. Evaporative cooling of circulating water. M.-L.: Gosenergoizdat, 1949, 440 pages.

[2] V.S. Ponomarenko. Cooling towers of industrial and energy enterprises: a reference manual / V. S. Ponomarenko, Yu. I. Arefiev; under the editorship of V.S. Ponomarenko. - M.: Energotomizdat, 1998. - 376 pages.

[3] V. Ye. Gmurman. Probability theory and mathematical statistics: a training manual / V. E. Gmurman. M.: Higher school, 1992, 512 pages.

[4] F.M. Davletshin,A.A. Sagdeev,K.Kh. Gilfanov. The experimental model for studying the characteristics of the irrigators of industrial cooling towers // Chemistry and Chemical Technology. 2006. Vol.49 Issue 12. pp. 90 92.

[5] V.A. Kalatuzov. Mathematical model for calculating regulatory characteristics // Energy conservation and water treatment. №.4 (42). 2006.

[6] N. Williamson, S. Armfeld, M. Behnia. Numerical simulation of flow in a natural draft wet cooling tower The effect of radial thermofluid fields // Applied Thermal Engineering. February 2008, Vol. Issues 1-2, pp. 178 189.

[7] Xiaoxiao Li, Lin Xia, Hal Gurgenci, Zhiqiang Guan. Performance enhancement for the natural draft dry cooling tower under crosswind condition by optimizing the water distribution // Inter. J. of Heat and Mass Transfer.

№. 107. 2017.

[8] Yubiao Sun, Zhigiang Guan, Hal Gurgenci, Kamel Hooman, Xiaoxiao Li, Lin Xia. Investigation on the influence of injection direction on the spray cooling performance in natural draft dry cooling tower // International Journal of Heat and Mass Transfer. Vol. 110. 2017. pp. 113-114.

[9] Tao Ning, Daotong Chong, Mingxiao Jia, Jinshi Wang, Junjie Yan.

Experimental investigation on the performance of wet cooling towers with defects in power plants // Applied Thermal Engineering. Volume 78, March 5, 2015, pages 228-235.

[10] Ali Ayoub, Blaze Gjorgiev, Giovanni Sansavini. Cooling towers performance in a changing climate: Technoeconomic modeling and design optimization // Energy. Volume 160, 1 October 2018, pages 1133-1143. 